\title{
A Not So Sudden Impact-Historical Relations Between Conifers and Insects Can Help Predict Damage by Nonnative Insects
}

\section{Nonnative Insects are a Growing Threat to North American Forests}

The arrival and establishment of nonnative insects in North America is increasingly problematic. International trade has created opportunities to move wood products and nursery stock worldwide, which has increased the risk of insect introduction to regions or countries where they are not native. Globally, damage by nonnative insects has been estimated to be more than $\$ 70$ billion a year. An example of the significance of the problem in the United States is the estimated $\$ 12.7$ billion spent through 2020 in response to the invasion of the emerald ash borer, a metallic-colored woodboring beetle native to Asia that attacks and kills ash (Fraxinus spp.) trees.

Increased tree mortality threatens the many plant and animal species that rely on forests for habitat; for example, the loss of eastern hemlock as a result of the nonnative hemlock woolly adelgid (Adelges tsugae) has negatively impacted bird species, such as the black-throated green warbler and Acadian flycatcher. Damage to forests also diminishes their ability to provide shade, beauty, and outdoor recreational opportunities and negatively impacts the forest's contribution to the maintenance of biodiversity, water quality, and carbon sequestration. Many nonnative insect species have made their way to North America, yet only a small percentage of established nonnative insects cause widespread mortality of native trees. The ability to predict which newly arriving insects will damage trees could help those tasked with managing tree and forest health but achieving this level of insight has proved challenging.

\section{Working Together to Predict the Next High-impact Insect Invasion}

One group of researchers, the High-impact Insect Invasions Working Group (HIIWG), has developed a predictive tool to estimate the likelihood that a newly arriving nonnative insect may significantly impact North American conifers.

The HIIWG examined several traits and

factors associated with nonnative

insects already established in

North America.
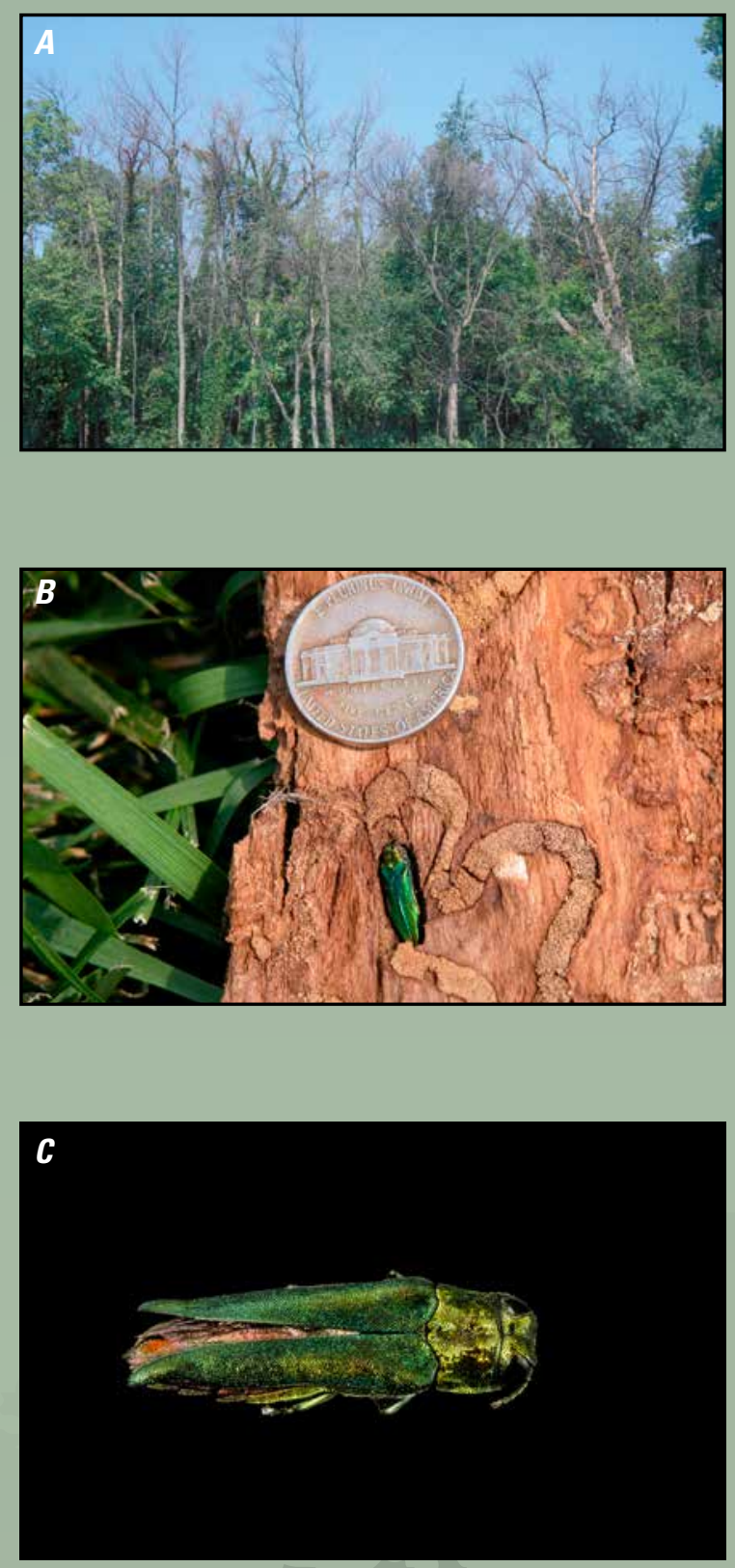

Ash tree mortality in North America $(A)$ from the emerald ash borer (Agrilus planipennis), a nonnative insect $(B, C)$, is an example of high-impact damage on a hardwood. Photographs by Daniel Herms, The Ohio State University, Bugwood.org $(A)$; Eric R. Day, Virginia Polytechnic Institute and State University, Bugwood.org (B); and the U.S. Geological Survey Bee Inventory Monitoring Lab (C). 
They developed a nine-point scale to describe the level of damage nonnative insects can cause, ranging from low impact, which produces minor damage on a single tree (for example, needle loss, fruit or cone damage) to high impact damage that causes the death of tree populations in forests and urban landscapes, or local extinctions (Mech and others, 2019).

Literature reviews on nonnative insects that feed solely on cone-bearing trees, such as pines, firs, and spruces (hereafter, we refer to these nonnative insects in North America as conifer specialists) provided large amounts of data on the traits of the conifer specialists, traits of the trees on which they feed (host trees), and lists of native insects that also feed on the same trees. These data were compiled into the Traits and Factors Catalog (TRAFAC), a database for conifer specialists already established in the United States (Mech and others, 2020). Using these data, the HIIWG identified which factor (or combination of factors) best predicted the risk that a conifer specialist would have a high impact, and then developed a statistical model to predict the probability that a conifer specialist yet to arrive in North America would cause significant damage to conifers if the insect became established (Mech and others, 2019).

\section{Nonnative Conifer-specialist Insects Already in the U.S. and Their Impact}

Published lists of nonnative insects in North America document 58 nonnative insects that feed solely on native conifer trees in North America. These conifer specialists represent five insect orders and five feeding guilds, with the majority being sap-feeders in the order Hemiptera, such as adelgids, aphids, and scales. Of the 58 conifer specialists, approximately 69 percent had little or no impact on trees, 19 percent had a medium impact on trees, and 12 percent had a high impact. All highimpact conifer specialists were either sap-feeding Hemipterans such as the balsam woolly adelgid (Adelges piceae), hemlock woolly adelgid, and red pine scale (Matsucoccus matsumurae) or needle-feeding Hymenopterans such as the European spruce sawfly (Gilpinia hercyniae), pine sawfly (Diprion similis), and larch sawfly (Pristiphora erichsonii). Forty-nine of the nearly 100 native North American conifers were fed upon by at least 1 conifer specialist, and some species had as many as 21 conifer specialists that could feed on them. Most of the conifer specialists fed on more than 1 species of conifer, with some feeding on as many as 16 different conifer species.
Insect Traits were not Useful Predictors of Impact

Eight traits were examined for their ability to predict the impact of the insect on its host tree: (1) the number of generations in a year, (2) feeding guild (for example, a folivore [which feeds on leaves] or a sap-feeder), (3) home range, (4) reproductive strategy (sexual or asexual), (5) fecundity (number of offspring in each generation), (6) pest status (whether the insect is considered an aggressive pest in its native range), (7) the number of tree genera the insect feeds on in its home range, and (8) the mechanism of dispersal (for example, flying, wind-dispersed, crawling). None of these traits, separately or in combination, had any predictive value.

\section{Some Conifer Traits Help Predict the Impact of Nonnative Insects}

Six traits were examined for each conifer species: (1) foliage texture, (2) growth rate, (3) drought tolerance, (4) fire tolerance, (5) shade tolerance, and (6) wood density. The researchers found that if a tree was highly tolerant of shade but not tolerant of drought, a conifer specialist was more likely to cause high-impact damage to that tree. Examples of trees with these traits include many firs (Abies), spruces (Picea), and hemlocks (Tsuga). For example, eastern hemlock is one of the most shade-tolerant trees, with seedlings able to survive in only 5-percent sunlight, but it has low drought tolerance and is currently experiencing widespread mortality from the nonnative hemlock woolly adelgid. Scientists previously predicted that shade-tolerant trees evolved strong defenses to insects feeding upon them. However, these results instead indicate that if a conifer specialist can overcome the defenses of a tree that is shade adapted, the tree may not be able to tolerate the insect's feeding damage.

\section{Evolutionary Relatedness Between an Insect's Home Range and North American Host Trees is an Important Predictor}

The researchers also examined the evolutionary divergence time (in this case, millions of years ago [Ma]) between a conifer specialist's home range host tree and North American host trees. Divergence time is used to estimate the genetic relatedness between the home range host and North American host trees.

\section{Low Impact}

\section{No documented damage}

\section{Minor damage}

\section{Medium Impact}

\section{Kills stressed tree}

4 Weakens tree; another agent causes mortality

\section{Kills healthy tree}

The nine-point impact scale categorizes the levels of damage a nonnative insect may cause. The impact scale was developed and tested by the High-impact Insect Invasions Working Group (HIIWG; Schulz and others, 2020). The HIIWG used the impact score to assign high, medium, or low impact designations to the 58 nonnative conifer specialists identified in North America.

\section{High Impact}

\section{Isolated mortality within a population of trees}

\section{Extensive or persistent mortality in a population}

\section{Wave of mortality across a region}
Functional extinction of the host plant 


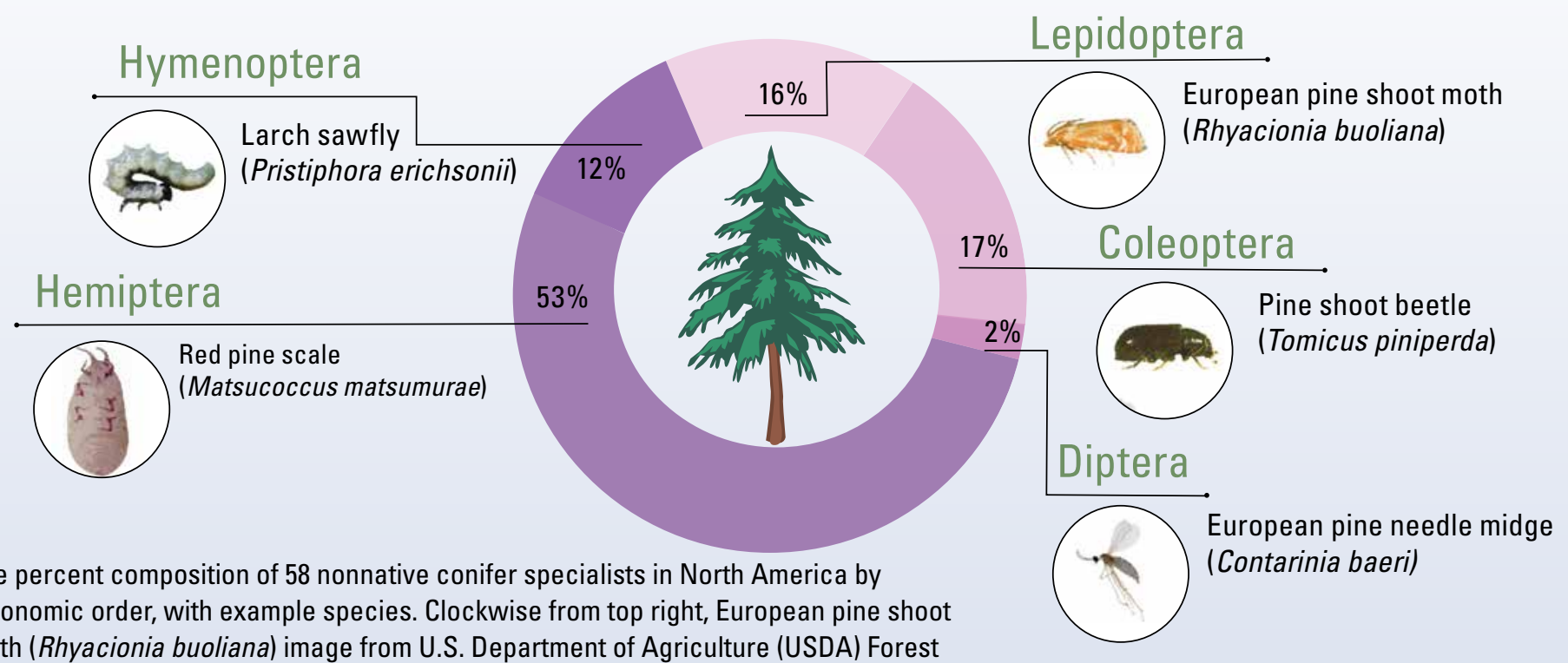
moth (Rhyacionia buoliana) image from U.S. Department of Agriculture (USDA) Forest

Service-Ogden, Bugwood.org; pine shoot beetle (Tomicus piniperda) from Maja Jurc, University of Ljubljana, Bugwood.org; European pine needle midge (Contarinia baeri) from Susan Ellis, USDA APHIS PPO (Animal and Health Inspection Service, Plant Protection and Quarantine), Bugwood.org; red pine scale (Matsucoccus matsumurae) from Alessandra Rung, Scale Insects, USDA APHIS PPQ, Bugwood.org; and larch sawfly (Pristiphora erichsonii) from Steven Katovich, Bugwood.org.

The effect of divergence time on conifer-specialist impact was found to depend on the insect's method of feeding. If the conifer specialist feeds on foliage and its North American host tree diverged from its home range host between 5 and $1.5 \mathrm{Ma}$, there is a 75-percent chance the conifer specialist will cause highimpact damage on the North American host tree. However, if the time of divergence was longer or shorter, then there is a much smaller chance the insect will have a high impact. If the conifer specialist is a sap-feeder, it has the greatest chance of having a high impact on North American conifers that diverged from the home range host between 17 and $12 \mathrm{Ma}$. One explanation for these trends may be that North American conifers that diverged more recently from the home range conifers may still produce chemical defenses similar to those of the home range conifer, the tree with which the insect coevolved. The North American conifers may then retain the ability to defend against the newly arrived conifer specialist. Conversely, after more than $5 \mathrm{Ma}$ (foliage feeders) or $17 \mathrm{Ma}$ (sap feeders), the North American host trees may have genetically diverged from the home range host trees enough to be only marginally suitable for feeding by the conifer specialist.
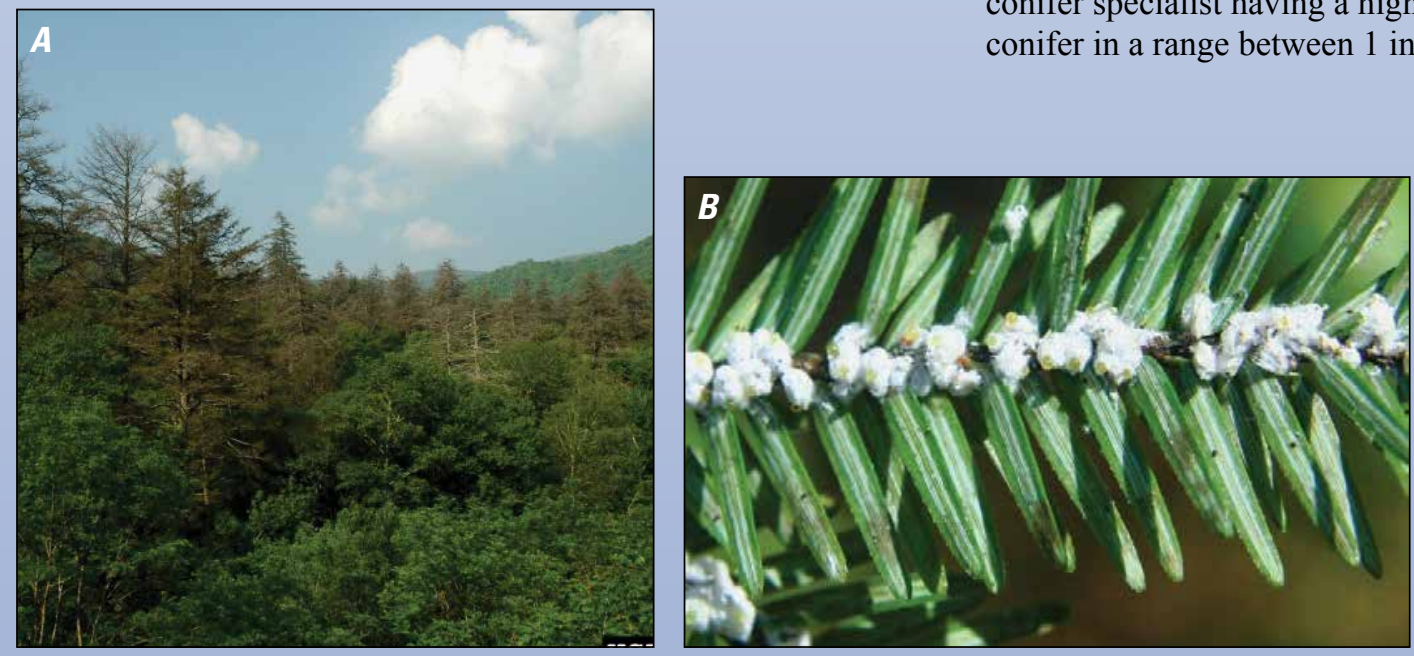

\section{Evolutionary Relatedness of Native and Nonnative Insects on the Same Conifer is an Important Predictor}

If a North American conifer had an insect native to North America feeding on it that was in the same genus as the conifer specialist (a congener), then the likelihood of highimpact damage was reduced. There are a number of reasons that might explain this finding, such as (1) the tree's chemical defenses against the native insect may also deter a nonnative conifer specialist, (2) natural enemies of the native insect may also attack the conifer specialist, or (3) competition between the native insect and conifer specialist may reduce the conifer specialist's ability to be successful.

\section{Predicting Nonnative Insect Impact on Trees}

The statistical model developed by the HIIWG was best able to predict the probability that a newly established conifer specialist will cause mortality of North American conifers when conifer traits, host tree divergence time, and the presence of a native congener were all included in the model. Using these three factors, the model calculates the odds of any particular conifer specialist having a high impact on a North American conifer in a range between 1 in 6.5 to 1 in 2,858 (Mech and
Eastern hemlock tree mortality in North America $(A)$ from the hemlock woolly adelgid (Adelges tsugae) (B), an insect accidentally introduced from Japan. Photographs by William M. Ciesla, Forest Health Management International, Bugwood.org $(A)$, and Tom Coleman, U.S. Department of Agriculture Forest Service, Bugwood.org (B). 


\section{The High-impact Insect Invasions Working Group}

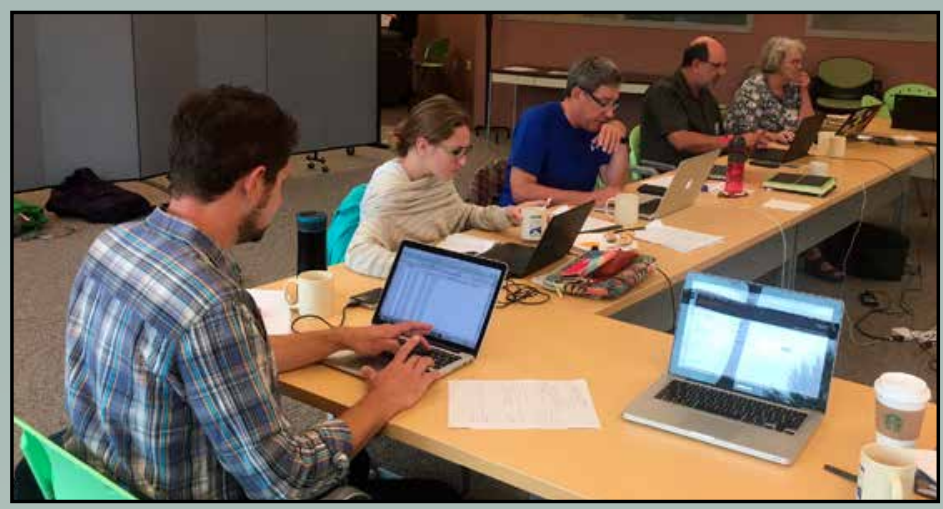

Photograph by Nathan Havill, U.S. Forest Service, used with permission.

The High-impact Insect Invasions Working Group (HIIWG) is a multidisciplinary group of scientists interested in nonnative insect invasions on woody plants. They have been funded by the John Wesley Powell Center for Analysis and Synthesis and the National Urban and Community Forestry Advisory Council. Partners associated with the High-impact Insect Invasions Working Group:

Arkansas State University

Colorado State University

Dartmouth College

Davey Tree Expert Company

Indiana University

Stony Brook University

University of Georgia

University of Maine

By Lekeah A. Durden, U.S. Geological Survey-NSF Graduate

Student Intern; Ashley N. Schulz, Colorado State University; Angela Mech, University of Maine, Orono; Kathryn A. Thomas,

U.S. Geological Survey

Edited by Katherine Jacques

Layout and design by Kimber Petersen

\section{For more information contact}

Kathryn A. Thomas: kathryn_a_thomas@usgs.gov

Any use of trade, product, or firm names is for descriptive purposes only and does not imply endorsement by the U.S. Government. others, 2019). Furthermore, the HIIWG continues their efforts by (1) applying the predictive model to insect species that are not established in North America but have a high chance of arriving through trade or accidental introduction, (2) evaluating the factors that could predict the impact of nonnative insects that feed solely on single families of seed-bearing trees and shrubs (woody angiosperms), (3) evaluating the factors that predict the impact of nonnative insects that are generalists (that is, they feed on a wider range of trees), and (4) developing a software application, to be distributed through the set of national i-Tree tools (https://www.itreetools.org/), to help determine of the risk posed by newly arriving tree feeding nonnative insects.

\section{Societal Benefits}

By focusing on insects that pose the highest threat, managers and decision-makers can prioritize funds for preemptive management strategies and form effective policies that deter the introduction of high-impact insects not yet established in North America. The statistical model created by the HIIWG for nonnative conifer specialists is a valuable tool to help identify those invading insects with the potential to be the most damaging if the insect becomes established in North America. In addition, application of tools like this model can increase positive environmental outcomes for land managers by focusing their efforts on conifer populations that are deemed most vulnerable to extensive mortality. These findings can help to maintain the health of U.S. forests and ensure these habitats remain healthy and available for the enjoyment of future generations.

\section{References Cited}

Mech, A.M., Thomas, K.A., Havill, N.P., Schulz, A.N., and Tobin, P.C., 2020, Traits and Factors Catalog (TRAFAC)Conifer specialists of North America: U.S. Geological Survey data release, https://doi.org/10.5066/P9CLFQMI.

Mech, A.M., Thomas, K.A., Marsico, T.D., Herms, D.A., Allen, C.R., Ayres, M.P., Gandhi, K.J.K., Gurevitch, J., Havill, N.P., Hufabauer, R.A., Liebhold, A.M., Raffa, K.F., Schulz, A.N., Uden, D.R., and Tobin, P.C., 2019, Evolutionary history predicts high-impact invasions by herbivorous insects: Ecology and Evolution, v. 9, no. 21, p. 12216-12230. [Also available at https://doi.org/10.1002/ece3.5709.]

Schulz, A.N., Mech, A.M., Allen, C.R., Ayres, M.P., Gandhi, K.J.K., Gurevitch, J., Havill, N.P., Herms, D.A., Hufbauer, R.A., Liebhold, A.M., Raffa, K.F., Raupp, M.J., Thomas, K.A., Tobin, P.C., and Marsico, T.D., 2020, The impact is in the details-Evaluating a standardized protocol and scale for determining non-native insect impact: Neobiota, v. 55, p. 61-83. [Also available at https://doi.org/10.3897/ neobiota.55.38981.]

\section{,

